\title{
Tides in Three Enclosed Basins: The Baltic, Black, and Caspian Seas
}

\author{
Igor P. Medvedev ${ }^{1,2 *}$, Alexander B. Rabinovich ${ }^{1,3}$ and Evgueni A. Kulikov ${ }^{1}$ \\ ${ }^{1}$ P. P. Shirshov Institute of Oceanology, Russian Academy of Sciences, Moscow, Russia, ${ }^{2}$ Roshydromet, Fedorov Institute of \\ Applied Geophysics, Moscow, Russia, ${ }^{3}$ Department of Fisheries and Oceans, Institute of Ocean Sciences, Sidney, BC, \\ Canada
}

Tides are the main type of sea level variability in the world oceans. However, oceanic tides penetrate weakly, or do not penetrate at all, into enclosed basins such as the Baltic, Black, and Caspian seas. Consequently, only directly forced tides are formed in these basins. Long observation time series (up to 123 years in the Baltic Sea and 38 years in the Black and Caspian seas) at numerous stations were used to precisely estimate tidal constituents. High-resolution spectra revealed fine structure of discrete peaks at tidal frequencies. The diurnal radiational constituent $S_{1}(1 \mathrm{cpd})$, apparently associated with breeze winds, was found to play an important role in general tidal dynamics in these seas. Harmonic analysis of tides for individual yearly series with consecutive vector averaging over the entire observational period was applied to estimate mean amplitudes and phases of tidal constituents. Our findings indicate that the formation and predominance of

OPEN ACCESS

Edited by:

Francisco Mir Calafat,

Natural Environment Research

Council, UK

Reviewed by:

João Miguel Dias,

University of Aveiro, Portugal Xiangbo Feng,

University of Reading, UK

*Correspondence:

Igor P. Medvedev medvedev@ocean.ru

Specialty section:

This article was submitted to Coastal Ocean Processes, a section of the journal Frontiers in Marine Science

Received: 01 December 2015 Accepted: 23 March 2016 Published: 14 April 2016

Citation: Medvedev IP, Rabinovich $A B$ and Kulikov EA (2016) Tides in Three Enclosed Basins: The Baltic, Black, and Caspian Seas.

Front. Mar. Sci. 3:46.

doi: 10.3389/fmars.2016.00046 diurnal or semidiurnal tides in these seas appears to depend on the frequency-selective properties of the basins. Thus, in the Baltic Sea with fundamental eigen period of about $27 \mathrm{~h}$, diurnal tides dominate in the major eastern gulfs. In the Black Sea amplification of semidiurnal tides is observed in the northwestern part, and is likely associated with local resonance. The predominance of semidiurnal tides in the Caspian Sea has also probably a resonant nature. Maximum tidal heights estimated for a 100-year period are $23 \mathrm{~cm}$ in the Baltic Sea, $18 \mathrm{~cm}$ in the Black Sea and $21 \mathrm{~cm}$ in the southern Caspian Sea.

Keywords: tides, tide gauges, Baltic Sea, Black Sea, Caspian Sea, seiches, sea-level spectra

\section{INTRODUCTION}

Tides are the major type of sea level oscillations in the world oceans. Maximum amplitudes of tides are mainly observed in coastal waters of certain marginal seas. Into isolated inland seas, such as the Black, Caspian and Baltic seas, oceanic tides penetrate weakly, or do not penetrate at all. The Baltic Sea is a large enclosed shallow sea connected to the North Sea through the narrow and shallow Danish straits. The Black Sea has limited water exchange with the Mediterranean Sea through the Turkish Straits (the Bosporus, the Sea of Marmara, and the Dardanelles). Tides from neighboring basins have small influence on tidal oscillations in these seas. The Caspian Sea is the largest entirely enclosed inland body of water on the Earth; consequently, only directly forced tides are formed in this sea.

Despite their small amplitudes, tides in all these seas are scientifically interesting and important; their accurate assessment is crucial for the understanding of the overall dynamics of the respective basins. Tides produce regular periodic oscillations of sea level and currents; other processes superimpose the tidal background. The mechanism responsible for the formation of tides in these seas is in many ways similar to the mechanism of formation of eigen sea modes (seiches) and 
storm surges, in particular, the destructive surges in the Gulf of Finland, the Baltic Sea (Kulikov and Medvedev, 2013).

Tidal oscillations in the Baltic Sea and in the Black Sea have been studied for over 100 years, but the nature of their anomalous features is still not sufficiently clear (Defant, 1961; Engel, 1974). Tides in the Caspian Sea have been examined very little and mainly as part of more general investigations of sea level oscillations in this basin (cf. German, 1970; Levyant et al., 1994). Studies of tides in these seas are based on relatively short series of tide gauge data ( $\leq 1$ year). The accuracy of these calculations is limited because of the small tidal signal in comparison with the background noise level ( $\mathrm{s} / \mathrm{n}$ ratio). Long time series of highquality observations are necessary to precisely estimate tidal constituents in these seas.

Medvedev et al. (2013) used multi-year (5-31 years) hourly data-sets from 35 tide gauge stations to examine tidal oscillations in the Baltic Sea. High-resolution spectral analysis revealed fine structure of tidal harmonics exceeding the noise level. In the last three years, the authors were able to collect a large amount of additional tide gauge data for the Baltic Sea, allowing more detailed study. Furthermore, it became interesting to compare the tidal character and generation mechanism in the Baltic Sea with those in two other large European inland seas: the Black and Caspian. In the present study, we used long-term hourly observations from a great number of coastal tide gauges to accurately evaluate tides in these three seas and compare their principal features.

\section{OBSERVATIONS}

In the Baltic Sea we used data from 38 stations located along the coasts of Russia, Latvia, Lithuania, Estonia, Poland, Germany, Denmark, Sweden, and Finland. The mean duration of sea-level records in this sea was $\sim 17$ years; the longest series of $>100$ years were at six Swedish stations. In the Black Sea we used sea level series from 23 stations on the Russian, Ukrainian and Georgian coasts. The maximum length of 38 years was at Tuapse (northeastern coast); the mean length of the series was 17 years. In the Caspian Sea observations from 11 stations on the coasts of Russia, Kazakhstan, Azerbaijan, and Turkmenia were used, with a maximum duration of 38 years at Makhachkala (northwestern coast) and a mean length of 11 years. The series of observations were carefully checked; shifts and spikes were eliminated, short gaps (shorter than 1 day) were interpolated.

\section{TIDAL SPECTRA}

To examine the spectral properties of sea level oscillations we used a procedure similar to that described by Thomson and Emery (2014). To improve the spectral estimates, we applied a Kaiser-Bessel (KB) spectral window with half-window overlaps prior to the Fourier transform. The length of the window was chosen to be $8192 \mathrm{~h}$, yielding DOF (degrees of freedom) from 22 (Aladga) to 158 (Stockholm). The spectral resolution for all spectra was $\Delta f \approx 0.00293$ cycles per day (cpd).

Six selected spectra (two for each sea) are shown in Figure 1A. They are divided into two groups: "deep-sea," for stations located on deep-sea coasts of the corresponding basins (left), and "shallow-water," for shallow-water coasts (right). The spectra are "red," with spectral energy decreasing with increasing frequency as $\omega^{-2}$, which is typical for the long wave spectra (cf. Rabinovich, 1993). The shape and depths of the sea determines the natural (eigen) frequencies of the basin. In particular, a wide spectral "hump" at frequencies $0.8-1.6 \mathrm{cpd}$ in the sea-level spectrum at Kronstadt (the Gulf of Finland, eastern part of the Baltic Sea) appears to be associated with the fundamental eigen period of $27 \mathrm{~h}$, dominant in this part of the Baltic Sea (Lisitzin, 1974; Jönsson et al., 2008; Kulikov and Medvedev, 2013).

The monotonic character of the continuum spectra is interrupted by prominent discrete peaks at tidal frequencies. These particular peaks are of primary interest for the present study. Four major tidal harmonics, are recognizable in most records: diurnal $\mathrm{K}_{1}$ (period of $23.93 \mathrm{~h}$ ) and $\mathrm{O}_{1}(25.82 \mathrm{~h}$ ), and semidiurnal $\mathrm{M}_{2}(12.42 \mathrm{~h})$, and $\mathrm{S}_{2}(12.00 \mathrm{~h})$. Although amplitudes of tidal constituents in isolated seas are small, because these oscillations are regular and deterministic, the respective spectral peaks are well-defined. In the Baltic Sea (everywhere, except the central part and the region of the Danish straits) diurnal peaks are predominant; in the Black and Caspian seas the semidiurnal tidal peaks prevail.

Multi-year series of tide gauge observations enabled us to provide the detailed tidal spectroscopy and to resolve individual tidal constituents. The high-resolution spectra can reveal specific properties of the tidal harmonics, which are unrecognizable in ordinary spectra. For the present analysis, we selected stations with the longest time series (the same as shown in Figure 1A) and used the following lengths for the Kaiser-Bessel spectral window: for Stockholm, Tuapse and Makhachkala, $N=2{ }^{17} \mathrm{~h}=131072 \mathrm{~h} \approx 5461$ days $(\Delta f \approx 0.000183 \mathrm{cpd}$ ); for Kronstadt and Odessa, $N=2^{16} \mathrm{~h}=65536 \mathrm{~h} \approx 2731$ days $(\Delta f \approx$ $0.000366 \mathrm{cpd}$ ), and for Aladga, $N=52584 \mathrm{~h} \approx 2191$ days ( $\Delta f \approx$ $0.000456 \mathrm{cpd}$ ). The results are shown in Figures 1B-D.

The high-resolution spectral peaks corresponding to the major diurnal $\left(\mathrm{Q}_{1}, \mathrm{O}_{1}, \mathrm{P}_{1}, \mathrm{~K}_{1}\right.$, and $\left.\mathrm{S}_{1}\right)$ and semidiurnal $\left(\mathrm{N}_{2}\right.$, $\mathrm{M}_{2}, \mathrm{~S}_{2}$, and $\mathrm{K}_{2}$ ) harmonics are clearly above the noise level and significantly exceed the $95 \%$ confidence spectral level. Even peaks related to some secondary constituents (e.g., $2 \mathrm{~N}_{2}, \mu_{2}$, and $\mathrm{L}_{2}$ ) are seen in these spectra, despite their tiny amplitudes. What is especially important, these high-resolution spectra allowed us to resolve tidal harmonics from the same groups, in particular, $P_{1}-S_{1}-K_{1}$ and $T_{2}-S_{2}-R_{2}-K_{2}$. As a result, we could identify an interesting feature related to the solar harmonic $S_{1}$. The gravitational input at this frequency is negligible; this harmonic is associated with radiational forcing, i.e., with the cumulative effect of sea-breeze winds, atmospheric tides and diurnal air/sea water temperature changes (Zetler, 1971; Wunsch, 1972; Pugh, 1987). The frequency $S_{1}$ is located between the frequencies of gravitational harmonics $K_{1}$ and $P_{1}$ and it is indistinguishable in the conventional (low-resolution) spectra (Figure 1A). However, in the high-resolution spectra (Figures 1B-D) the $S_{1}$ peak is clearly seen.

In the Baltic and Black seas the magnitude of $S_{1}$ is roughly equal to $P_{1}$, while in the Caspian Sea it is sufficiently greater than $\mathrm{O}_{1}, \mathrm{P}_{1}$, and $\mathrm{K}_{1}$. A substantial difference is evident in the 

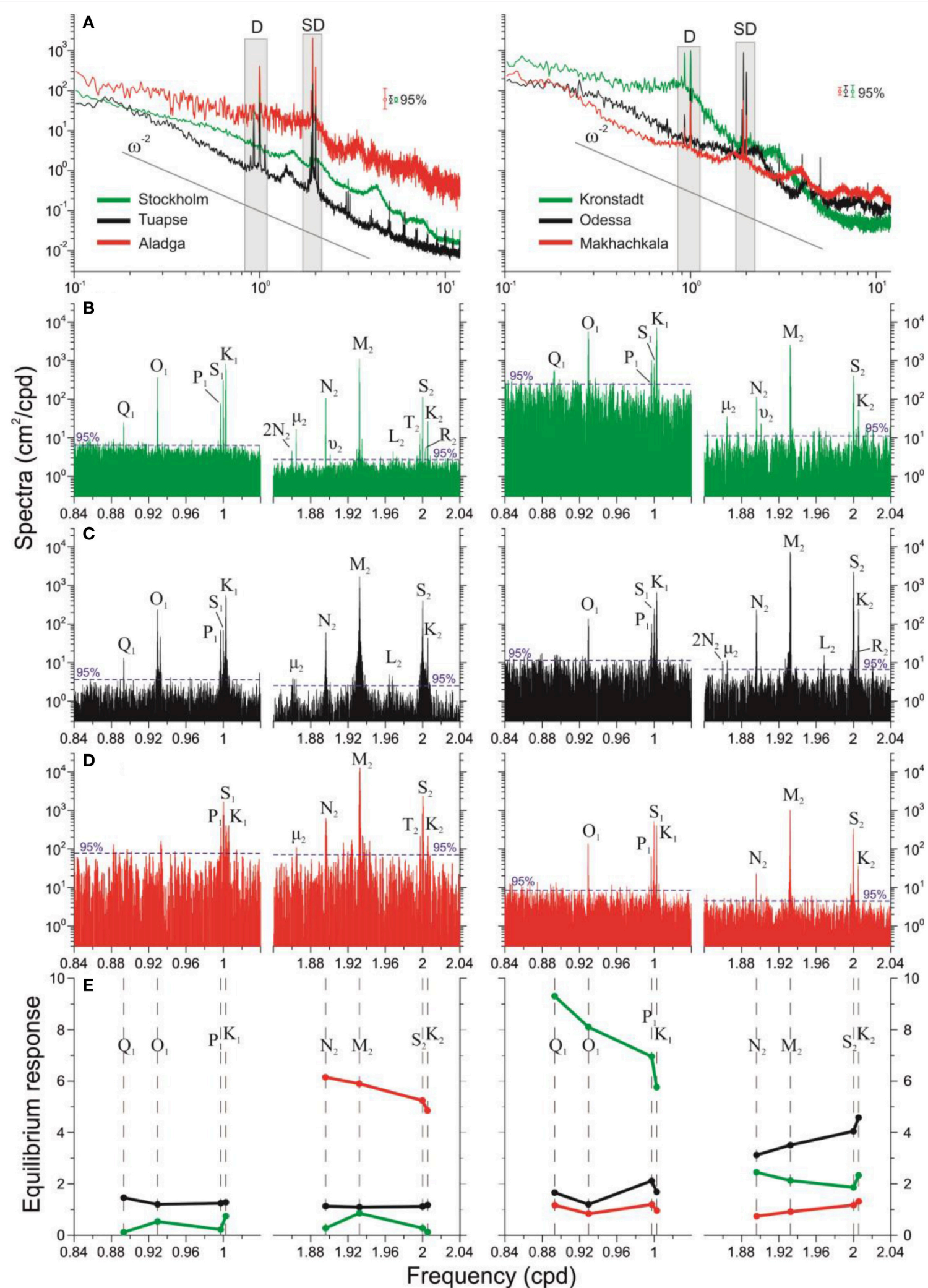

FIGURE 1 | Sea level spectra for six stations in the Baltic Sea (green), Black Sea (black), and Caspian Sea (red); the left column of plots is related to "deep-sea" stations, the right column to "shallow-water" stations. The stations are indicated in Figure 2. (A) Low-resolution spectra at six stations; the 95\% 


\section{FIGURE 1 | Continued}

confidence levels are shown, spectral power law $\omega^{-2}$ is denoted by a thin solid black line, shaded areas indicate diurnal (D) and semidiurnal (SD) tidal frequency bands shown in plots below. (B) High-resolution diurnal and semidiurnal spectra for Stockholm and Kronstadt, the Baltic Sea; main tidal peaks are indicated. (C) The same for Tuapse and Odessa, the Black Sea. (D) The same for Aladga and Makhachkala, the Caspian Sea. (E) The equilibrium response $R_{j}$, i.e., the ratio of observed and theoretical amplitudes of diurnal and semidiurnal tidal constituents for six selected "deep-sea" (left) and "shallow-water" (right) stations.

character of diurnal tides in the southern (deepest) part and other parts of the Caspian Sea. In particular, at Makhachkala (northwestern coast) $S_{1}$ is predominant, but other diurnal harmonics $\left(\mathrm{K}_{1}, \mathrm{O}_{1}\right.$, and $\left.\mathrm{P}_{1}\right)$ are prominent (Figure $1 \mathrm{D}$ right); the ratios between their amplitudes is close to theoretical for the tidal potential (e.g., Pugh, 1987). The diurnal tidal spectrum at Aladga (southern basin) is substantially different: the $\mathrm{O}_{1}$ peak is absent, while the $K_{1}$ and $P_{1}$ peaks are nearly equal and considerably smaller than $S_{1}$ (Figure $1 D$ left). A very similar effect was observed by Rabinovich and Medvedev (2015) for tidal oscillations in the Curonian Lagoon in the southeastern Baltic Sea: $\mathrm{S}_{1}$ strongly dominates, diurnal $\mathrm{O}_{1}$, and semidiurnal tidal harmonics are absent, while $\mathrm{K}_{1}$ and $\mathrm{P}_{1}$ are not related to the gravitational forcing, but to the seasonal modulation of the $S_{1}$ oscillations induced by sea-breeze winds and associated setup and set-down motions in the lagoon. We may assume that likewise, the observed diurnal tides in the southern part of the Caspian Sea are more related to the radiational effects than to gravitational forcing. Although amplitudes of diurnal radiational tidal sea level oscillations are relatively small, associated currents in the surface layer can be significant (cf. Zaytsev et al., 2010). At the same time, semidiurnal tides in the southern Caspian Sea are "classical": major gravitational tidal peaks $\left(\mathrm{M}_{2}\right.$, $\mathrm{N}_{2}$, and $\mathrm{K}_{2}$ ) are evident and their relative magnitudes are in agreement with tidal theory. The $\mathrm{S}_{2}$ tide is affected by radiational effects. We used the "credo of smoothness" (Zetler, 1971; Feng et al., 2015) to separate the gravitational and radiational components of $S_{2}$. In the Caspian and Baltic seas the mean ratio (radiational/gravitational) varies from 0.1 to 0.7 , and in the Black Sea from 0.05 to 0.6 . This is larger than the typical radiational contribution into $S_{2}$ of $\sim 16-17 \%$ (Zetler, 1971; Wunsch, 1972), probably because of weakness of gravitational tides in these seas.

In the Baltic Sea, despite their relatively small amplitude, not only major, but also several secondary harmonics are distinguishable in the spectra of Stockholm and Kronstadt (Figure 1B). In the Black Sea in addition to four major, a few secondary semidiurnal peaks are noticeable in the spectra of Tuapse and Odessa (Figure 1C).

To examine the generation properties of tides in various basins, we estimated the "equilibrium response":

$$
R_{j}=H_{j}^{\mathrm{obs}} / H_{j}^{\mathrm{eq}}
$$

i.e., the ratio of the observed amplitude of $j$-th harmonic $\left(H_{j}^{\text {obs }}\right)$ and the theoretical amplitude of the equilibrium tide $\left(H_{j}^{\mathrm{eq}}\right)$ (Pugh and Woodworth, 2014). Such responses for major diurnal and semidiurnal constituents for the deeper parts of the Baltic and Black seas are very similar and small. The reason of small $R_{j}$ for Stockholm is probably because this site is located near the $M_{2}$ and
$\mathrm{K}_{1}$ amphidromic points (cf. Medvedev et al., 2013). It is obvious that in both deep regions (central part of the Baltic Sea and eastern - Caucasian - part of the Black Sea) generation of tides has mainly non-resonant character. Diurnal and semidiurnal tides at other regions of the three seas have also non-resonant type of generation with $R_{j}$ small and almost uniform (Figure 1E). There are, however, three important exceptions:

\section{(1) Kronstadt, diurnal tides (Figure 1E right)}

The anomalous amplitudes of diurnal tides in the Gulf of Finland are found to be due to resonance with the fundamental gulf mode with a period $T \approx 27 \mathrm{~h}$ (Jönsson et al., 2008; Kulikov and Medvedev, 2013). The $R_{j}$ for Kronstadt and other sites located in this gulf increases sharply with decreasing frequency, i.e., approaching the fundamental gulf period: from $\sim 6.0$ for $\mathrm{K}_{1}\left(T_{j}=23.93 \mathrm{~h}\right)$ to 9.5 for $\mathrm{Q}_{1}\left(T_{j}=26.87 \mathrm{~h}\right)$. For semidiurnal tides $R_{j}$ in this region is approximately four times smaller and consistent. The strong prevalence of diurnal tides in the Gulf of Finland compared to semidiurnal tides (Figure 2) appears to be related specifically to this resonant effect. Similar resonance response for semidiurnal tides was observed by Sutherland et al. (2005) for Juan de Fuca Strait and by Arbic et al. (2007) for Ungava Bay.

(2) Odessa, semidiurnal tides (Figure 1E right)

The equilibrium response for semidiurnal tides in the shallow northwestern part of the Black Sea is significantly greater than for diurnal tides and gradually increases with increasing frequency: from 3.0 for $\mathrm{N}_{2}\left(T_{j}=12.66 \mathrm{~h}\right)$ to 4.5 for $\mathrm{K}_{2}\left(T_{j}=11.97 \mathrm{~h}\right)$. Probably this is due to the influence of the first seiche mode of the Black Sea, estimated by Maramzin (1985) to be $\sim 9.5 \mathrm{~h}$. This mode has maximum amplitudes specifically in the shallow northwestern part of the sea, in the vicinity of Odessa. In the background spectrum at Odessa, a "hump" with peak period of about $10 \mathrm{~h}$ is clearly seen (Figure 1A right).

(3) Aladga, semidiurnal tides (Figure 1E left)

As was indicated previously, gravitational diurnal tides are not observed in the southern basin of the Caspian Sea; that is why $R_{j}$ for these tides is not shown for Aladga. However, semidiurnal tides are noticeable in this region (Figure 1D left) and the respective $R_{j}$ are substantially larger than those for any other station shown in Figure 1E. The response increases with decreasing frequency (from 5.0 for $\mathrm{K}_{2}$ to 6.5 for $\mathrm{N}_{2}$ ). This appears to be related to the eigen mode with a period of about 14-15 h (Levyant et al., 1994).

In general, the results show that eigen modes of the corresponding basins appear to play an important role in formation of tides in the Baltic, Black, and Caspian seas. Also, the spectral analyses show the prevalence of tidal harmonics 
in comparison to the background noise, enabling us to use harmonic analysis to directly calculate tides.

\section{QUANTITATIVE AND SPATIAL CHARACTERISTICS OF TIDES}

We used the least squares method of harmonic analysis to estimate mean tidal amplitudes and phases of 14 tidal constituents, including diurnal, semidiurnal and higherfrequency. The analysis was done based on yearly series of observations for 38, 23, and 11 stations in the Baltic, Black, and Caspian seas, respectively. The results of the calculations for individual years were vectorly averaged over the entire observational period.

The computed amplitudes and phases were used to predict tides for a 100-year period (2001-2100) to take into account the 18.6-year nodal tidal variations and evaluate the maximum tidal heights. We also estimated specific tidal characteristics. Amplitudes of the major diurnal and semidiurnal constituents were used to calculate "form factor" (Pugh, 1987), i.e., the type of tides:

$$
F=\frac{H_{\mathrm{K}_{1}}+H_{\mathrm{O}_{1}}}{H_{\mathrm{M}_{2}}+H_{\mathrm{S}_{2}}} .
$$

The "Energy factor" was estimated as the ratio of the cumulative energy of diurnal $\left(H_{\mathrm{D} j}^{2}\right)$ and semidiurnal $\left(H_{\mathrm{SD} j}^{2}\right)$ harmonics:

$$
E_{f}=\sum_{j}^{N_{\mathrm{D}}} H_{\mathrm{D} j}^{2} / \sum_{j}^{N_{\mathrm{SD}}} H_{\mathrm{SD} j}^{2} .
$$

Maximum tidal heights and the energy factor in the three seas are shown in Figure 2.

In the Baltic Sea the amplitudes of the diurnal constituents $\mathrm{O}_{1}$ and $\mathrm{K}_{1}$ are approximately equal; the greatest amplitudes are observed in the head of the Gulf of Finland ( $\sim 3 \mathrm{~cm}$ in Kronstadt and Gorniy Institute) and in the Gulf of Riga (up to $1.8 \mathrm{~cm}$ ). Diurnal tides prevail in the eastern part of this sea: $F=6-8$ in

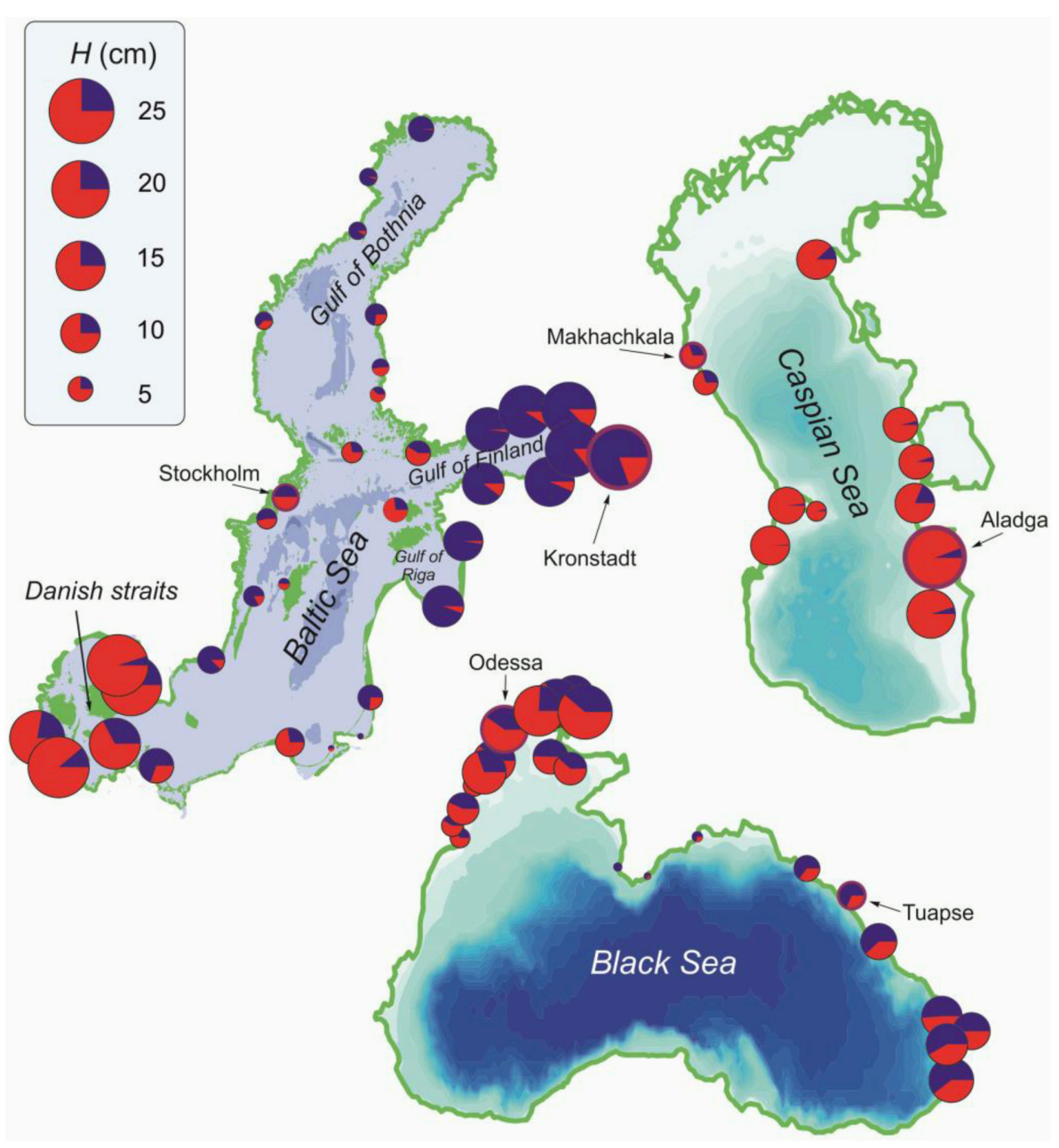

FIGURE 2 | Distribution of maximum tidal heights in the Baltic, Caspian, and Black seas evaluated for a 100-year period. The segment colors indicate relative contribution of diurnal (blue) and semidiurnal (red) energy into the total energy of the tidal oscillations. 
the Gulf of Finland, 4.5-6 in the Gulf of Riga, and 5-8 in the Gulf of Bothnia. The minimum diurnal amplitudes of $0.4 \mathrm{~cm}$ are observed in the central part of the Baltic Sea, where the $\mathrm{K}_{1}$ and $\mathrm{O}_{1}$ amphidromic points are situated. The maximum amplitude of the main semidiurnal harmonic $\mathrm{M}_{2}$ of about $6 \mathrm{~cm}$ is observed near the Danish straits, where the Baltic tides are influenced by semidiurnal tides arriving from the North Sea. The minimum $\mathrm{M}_{2}$ amplitudes of $0.2 \mathrm{~cm}$ are observed in the Gulf of Bothnia. The maximum cumulative tidal heights of $23 \mathrm{~cm}$ in the Baltic Sea occur in Neva Bay, in the easternmost part of the Gulf of Finland, and near the Danish straits.

The semidiurnal tides predominate in the main part of the Black Sea (cf. Engel, 1974; Fomicheva et al., 1991). The $\mathrm{M}_{2}$ amplitude in the northwestern part of the sea is $2.8-3 \mathrm{~cm}$, the diurnal harmonics $\mathrm{O}_{1}$ and $\mathrm{K}_{1}$ have amplitudes of 1.3-1.7 $\mathrm{cm}$, and $F=0.3-1.0$. The relatively high diurnal amplitudes in the northwestern part of the Black Sea (Figure 2) are caused by the radiational harmonic $S_{1}$, which is up to $4 \mathrm{~cm}$ on this coast. The maximum tidal heights of $18 \mathrm{~cm}$ are observed in the northwestern part of the sea (Kherson and Nikolayev). In the Caspian Sea tides also are of semidiurnal type $(F=0.2-0.9)$. The highest amplitude of the $\mathrm{M}_{2}$ harmonic is $5.4 \mathrm{~cm}$ at Aladga. The amplitudes of diurnal harmonics $\mathrm{O}_{1}$ and $\mathrm{K}_{1}$ in the Caspian Sea do not exceed $0.8-1 \mathrm{~cm}$. The maximum evaluated tidal height in the Caspian Sea is $21 \mathrm{~cm}$ on the southeastern coast of the sea. (Figure 2).

\section{CONCLUSIONS}

Long multi-year series of hourly sea level observations were used to examine tides in three large enclosed basins: the Baltic, Black, and Caspian seas. Despite relatively small amplitudes, tides were found to be evident in the sea level spectra as discrete spectral peaks significantly exceeding the background noise level. This enabled us to evaluate tides based on both spectral and harmonic analysis.

\section{REFERENCES}

Arbic, B. K., St-Laurent, P., Sutherland, G., and Garrett, C. (2007). On the resonance and influence of the tides in Ungava Bay and Hudson Strait. Geophys. Res. Lett. 34, L17606. doi: 10.1029/2007GL030845

Defant, A. (1961). Physical Oceanography, Vol. 2. Oxford: Pergamon Press.

Engel, M. (1974). Hydrodynamisch-numerische Ermittlung von Beweungsvorgängen im Schwarzen Meer. Mitteilungen Inst. Meereskunde Univ. Hamburg. 22, 1-71.

Feng, X., Tsimplis, M. N., and Woodworth, P. L. (2015). Nodal variations and longterm changes in the main tides on the coasts of China. J. Geophys. Res. Oceans 120, 1215-1232. doi: 10.1002/2014JC010312

Fomicheva, L. A., Rabinovich, A. B., and Demidov, A. N. (1991). "Sea level," in Hydrometeorology and Chemistry of the USSR Seas, Vol. 4, The Black Sea, eds A. I. Simonov and E. N. Altman (St. Petersburg, Russia: Gidrometeoizdat), 329-354.

German, V. Kh. (1970). Spectral analysis of sea level fluctuations in the Sea of Azov, Black and Caspian seas in the frequency range from one cycle per several hours to one cycle per several days. $T r$. GOIN. 103, 52-73.
Our findings indicate that the formation and predominance of diurnal or semidiurnal tides in these seas depends on the frequency-selective properties of the basins. Thus, in the Baltic Sea with fundamental eigen period of about $27 \mathrm{~h}$, diurnal tides dominate in the major eastern gulfs. In the Black Sea, resonant amplification of semidiurnal tides appears to be observed in the northwestern part. The predominance of semidiurnal tides in the Caspian Sea also most likely has a resonant nature. The radiational tides associated with solar radiational forcing on the sea surface were found to play an important role in the general tidal regime in these three seas. Maximum tidal heights estimated for a 100-year period are $24 \mathrm{~cm}$ in the Baltic Sea, $18 \mathrm{~cm}$ in the Black Sea, and up to $21 \mathrm{~cm}$ in the southern part of the Caspian Sea.

The accurate assessment of tides is crucial for the understanding the overall dynamics of these three seas. Tides produce regular periodic oscillations of the sea level and currents, and influence the general motions in these basins. All the other processes superimpose tidal background.

\section{AUTHOR CONTRIBUTIONS}

IM coordinated the work on the manuscript, wrote the initial version of the manuscript and prepared the figures. AR revised the text and figures substantially, EK did a substantial polishing of text. All authors actively contributed to the development of the manuscript idea, to its writing and preparation of figures.

\section{ACKNOWLEDGMENTS}

We gratefully acknowledge Fred Stephenson (Institute of Ocean Sciences, Sidney, BC, Canada) for valuable comments and suggestions. This work was supported by the Russian Foundation for Basic Research (grants 15-05-05986 and 16-35-60071), the Russian Science Foundation (grant 14-50-00095) and funds of P.P. Shirshov Institute of Oceanology.

Jönsson, B., Döös, K., Nycander, J., and Lundberg, P. (2008). Standing waves in the Gulf of Finland and their relationship to the basin-wide Baltic seiches. J. Geophys. Res. 113, C03004. doi: 10.1029/2006jc003862

Kulikov, E. A., and Medvedev, I. P. (2013). Variability of the Baltic Sea level and floods in the Gulf of Finland. Oceanology 53, 145-151. doi: 10.1134/s0001437013020094

Levyant, A. S., Rabinovich, B. I., and Rabinovich, A. B. (1994). Computation of seiche oscillations in seas of arbitrary configuration (exemplified by the Caspian Sea). Oceanology 33, 588-598.

Lisitzin, E. (1974). Sea Level Changes. Amsterdam: Elsevier.

Maramzin, V. Ya. (1985). "Computation of seiche oscillations by the finite element method in basins of arbitrary shape," in Theoretical and Experimental Investigations of Long Wave Processes, eds V. M. Kaistrenko and A. B. Rabinovich (Vladivostok: Far Eastern Scientific Center, USSR Academy of Sciences), 104-114.

Medvedev, I. P., Rabinovich, A. B., and Kulikov, E. A. (2013). Tidal oscillations in the Baltic Sea. Oceanology 53, 526-538. doi: 10.1134/s00014370130 50123

Pugh, D. T. (1987). Tides, Surges and Mean Sea-Level. Chichester: John Wiley. 
Pugh, D., and Woodworth, P. (2014). Sea-Level Science: Understanding Tides, Surges, Tsunamis and Mean Sea-Level Changes. Cambridge: Cambridge University Press.

Rabinovich, A. B. (1993). Long Ocean Gravity Waves: Trapping, Resonance and Leaking. St. Petersburg, Russia: Gidrometeoizdat.

Rabinovich, A. B., and Medvedev, I. P. (2015). Radiational tides at the southeastern coast of the Baltic Sea. Oceanology 55, 319-326. doi: 10.1134/S0001437015030133

Sutherland, G., Garrett, C., and Foreman, M. (2005). Tidal resonance in Juan de Fuca Strait and the Strait of Georgia. J. Phys. Oceanogr. 35, 1279-1286. doi: 10.1175/JPO2738.1

Thomson, R. E., and Emery, W. J. (2014). Data Analysis Methods in Physical Oceanography, Third and Revised Edition. New York, NY: Elsevier.

Wunsch, C. (1972). Bermuda sea-level in relation to tides, weather and baroclinic fluctuations. Rev. Geophys. Space Phys. 10, 1-49. doi: 10.1029/RG010i001p 00001
Zaytsev, O., Rabinovich, A. B., Thomson, R. E., and Silverberg, N. (2010). Intense diurnal surface currents in the Bay of La Paz, Mexico. Cont. Shelf Res. 30, 608-619. doi: 10.1016/j.csr.2009.05.003

Zetler, B. D. (1971). Radiational ocean tides along the coasts of the United States. J. Phys. Oceanogr. 1, 34-38.

Conflict of Interest Statement: The authors declare that the research was conducted in the absence of any commercial or financial relationships that could be construed as a potential conflict of interest.

Copyright (C) 2016 Medvedev, Rabinovich and Kulikov. This is an open-access article distributed under the terms of the Creative Commons Attribution License (CC BY). The use, distribution or reproduction in other forums is permitted, provided the original author(s) or licensor are credited and that the original publication in this journal is cited, in accordance with accepted academic practice. No use, distribution or reproduction is permitted which does not comply with these terms. 